\title{
RISK FACTORS FOR STRESS FRACTURES AMONG FEMALE ATHLETES FROM DIFFERENT SPORTS
}

\author{
Diana Dimitrova, Evelina Miloshova \& Lyubomir Mladenov \\ National Sports Academy „Vassil Levski”, Sofia, Bulgaria
}

\begin{abstract}
Stress fractures (SF) may affect all people who participate in sporting activities, but most commonly, they occur in athletes. Female athletes seem to experience more stress fractures than their male counterparts. There is limited research assessing the stress fractures among Bulgarian athletes. The aim of this study was to describe the incidence of SF among female athletic population and to analyze the selected risk factors. Ninety-three female athletes from different sports aged 19.2 3.8 years were recruited for this cross-sectional retrospective study. They completed a questionnaire to provide information on demographic data, sport experience, history of SF, menstrual function, and life-style risk factors. They also completed Eating attitude test (EAT-26) and questions aimed at identifying the presence of extreme weight control behaviors. The athletes were divided into two groups depending on whether or not they had SF in the past. Crude odds ratios (OR) were calculated to assess the association of SF with the studied factors. A total of 21 (22.6\%) of the athletes reported at least one previous SF, with most injuries located in the lower extremity. The training factors and disordered eating traditionally believed to increase the risk for SF did not contributed to the development of SF in our study. Among all studied factors only the primary amenorrhea was significantly associated with an increased risk of SF (OR 6.56, 95\% CI:1.4-30.6). These results suggest that in female athletes with similar sport experience, anthropometric characteristics, prevalence of disordered eating psychopathology and behavioral and life-style factors, those with primary amenorrhea are more likely to have stress fractures.
\end{abstract}

Key words: stress fractures, risk factors, female athletes, EAT-26, menstrual dysfunction

\section{INTRODUCTION}

Stress fractures (SF) are weak spots or small cracks in the cortical bone tissue caused by repeated stress and continuous overuse that exceed the ability of the muscles to absorb the shock from overexertion. Breithraupt (1855) first described them in soldiers. SF are recognized as a common injury in competitive athletes and result in reduced performance, loss of training time, restriction of the athlete's participation (Roos et al., 2015; Schnackenburg et al., 2011; Snyder et al., 2006). The increased athletic participation and increased physical demands for competitive athletes in the last decades have become prerequisites for increasing the incidents of SF.

It is generally agreed that the incidents of SF are higher in females than in males. The research data about the prevalence of SF among female athletes vary considerably - between $4 \%$ and 52\% (Øyen et al., 2009).

A wide range of intrinsic and extrinsic risk factors for SF in athletic population has been identified (Chen et al., 2013; Sharma \& Heagerty, 2017). The potential risk factors include, but are not limited to age (Bennell et al., 1999) body weight and BMI (Nattiv, 2000), biologic and biomechanical factors, eating disturbances (Bennell et al., 1999; Cobb et al., 2007; Kelsey et al., 2007), menstrual irregularities (Bennell et al., 1999; Cobb et al., 2007; Cosman et al., 2013; Shaffer et al., 2006), type of sport (McCormick et al., 2012), training, environmental factors, lifestyle factors (Altarac et al., 2000; Sharma \& Heagerty, 2017; Wentz et al., 2011). A study of U.S. Army soldiers also found substantial differences in the risk of stress fracture (SF) among racial/ethnic groups (Bulathsinhala et al., 2017). However, there is very limited data assessing stress fracture risk in athletes of varying nationality.

Therefore, the aim of this preliminary study was to describe the incidence of SF among Bulgarian female competitive athletic population and to analyze the selected risk factors.

\section{MATERIAL AND METHODS}

This study is with cross-sectional retrospective design and was approved by the Ethics Committee of the National Sports Academy. It was conducted according to the guidelines written in the Declaration of Helsinki.

Ninety-three randomly selected volunteer female athletes from different sports aged between 16 and 
28 years (mean age 19.2 \pm 2.8 ) participated in the study. Exclusion criteria were sports experience of less than five years, weekly training duration of less than 6 hours/per week and pregnancy in the past 5 years.

All athletes after informed consent and detailed instructions completed comprehensive questionnaire consisting of four parts. In the first part of the questionnaire, participants provided information about their age, sporting experience, participation in competitions and competitive level. Self-reported weight and height were used to calculate Body Mass Index (BMI). Additionally, there were questions about the presence of selected life-style risk factors for SR, such as smoking, alcohol and caffeine containing beverages intake.

The second part of the questionnaire assessed the history of the stress fractures (SF). Presence of a stress fracture was accepted if they were diagnosed by a physician or confirmed by x-ray, bone scan, or magnetic resonance imaging. Based on the responses to this part of the questionnaire the participants were divided into two groups. The athletes with history of one or more SF comprised the stress fracture group $(\mathrm{SFG})(\mathrm{n}=21)$ and those without history of SF were control group (CG) $(n=72)$.

The third part of the questionnaire included the Eating attitude test (EAT-26), used as a screening tool for identifying eating disorders (ED) risk (Garner et al., 1982). EAT-26 is comprised of $26 \mathrm{qu}-$ estions that relate to attitudes, beliefs and behaviors concerning food, body shape and weight. The answers were rated in a four-point Likert scale ranging from 0 (never, rarely, sometimes), 1 (often), 2 (usually) and 3 (always).

A total score of 20 or above denotes a high level of concern about dieting, body weight and eating behaviors, which may indicate the existence of disturbed eating attitudes and behavior. EAT-26 included also four questions aimed at determining the presence of extreme weight control behaviors: self-reported binge eating, self-induced vomiting, use of laxatives, and treatment for eating disorders over the preceding six months.
The fourth part of the questionnaire was aimed at identifying the following menstrual irregularities: oligomenorrhea (menstrual bleeding at intervals longer than 36 days), primary amenorrhea (lack of menstruation cycles up to 16 years of age), and secondary amenorrhea (absence of menstruation cycle for 3 consecutive months after the onset of menarche). Female athletes were also asked to give information about the age at menarche and use of contraceptives.

Statistical analyzes were performed using SPSS23.0. Normality of all parametric variables was tested using Shapiro-Wilk normality test. Descriptive statistics (mean \pm standard deviation) were computed for sociodemographic variables (age, height, weight, BMI, sport experience) and for EAT-26 total score. The categorical data were presented as percentage. An independent samples t-test was used for evaluation of differences in the demographic characteristics and sport experience data of both groups.

Chi-square analyses were conducted to compare whether the categorical variables differed between SF group and C group. Crude odds ratios and 95\% confidential interval ( $95 \% \mathrm{CI})$ were calculated to determine whether a particular exposure is a risk factor for a SF. The .05 level of significance was selected to test the statistical hypotheses.

\section{RESULTS}

Ninety-three female athletes from different sports participated in this study and $21(22.6 \%)$ of them had sustained at least one SF. These athletes were categorized as stress-fracture group. Seven subjects in this group had recurrent fractures (two or more $\mathrm{SF}$ ). The total number of SF diagnosed by a physician or confirmed by $\mathrm{x}$-ray, bone scans, or magnetic resonance imaging was 32 . The highest was the proportion of the SF occurring in the lower limb (thigh, leg, ankle, foot and toes) (59.4\%), followed by the upper limb (arm, forearm, wrist and fingers) (21.9\%), spine (9.4\%), and pelvis (9.4).

Most of the fractures occurred during training $(71.9 \%)$, followed by those that occurred at other times $(28.1 \%)$, and no fractures were obtained during the competition. 
Table 1. Characteristics of stress fracture group and control groups in terms of the risk factors

\begin{tabular}{|c|c|c|c|c|}
\hline \multicolumn{2}{|r|}{ CHARACTERISTICS } & $\begin{array}{c}\text { SF group } \\
\mathbf{n}=21\end{array}$ & $\begin{array}{c}C \text { group } \\
n=72\end{array}$ & $\begin{array}{l}\text { Mean } \\
\text { diff. }\end{array}$ \\
\hline \multirow{14}{*}{ 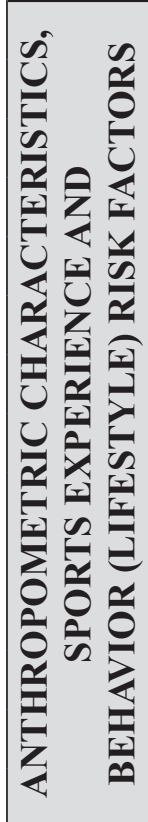 } & Age (years) & $20.52 \pm 2.8$ & $18.79 \pm 4.0$ & 1.73 \\
\hline & Height $(\mathrm{cm})$ & $168.48 \pm 7.8$ & $165.71 \pm 8.2$ & 2.77 \\
\hline & Weight (kg) & $58.43 \pm 8.8$ & $55.99 \pm 9.3$ & 2.44 \\
\hline & BMI $\left(\mathrm{kg} \cdot \mathrm{cm}^{-2}\right)$ & $20.55 \pm 2.6$ & $20.29 \pm 2.5$ & 0.26 \\
\hline & Training experience (years) & $10.35 \pm 3.9$ & $8.87 \pm 4.3$ & 1.48 \\
\hline & Weekly training duration (hours/week) & $14.95 \pm 6.8$ & $13.57 \pm 6.1$ & 1.38 \\
\hline & Age at commencing competition (years) & $9.73 \pm 3.4$ & $10.14 \pm 3.0$ & 0.41 \\
\hline & Participation in competitions & $80.95(17)$ & $88.89(64)$ & 7.94 \\
\hline & Smoking history: - never & $61.90(13)$ & $76.39(55)$ & 14.49 \\
\hline & - in the past or currently & $38.10(8)$ & $23.61(17)$ & 14.49 \\
\hline & Alcohol intake: $\quad$ - never & $57.14(12)$ & $70.83(51)$ & 13.69 \\
\hline & - in the past or currently & $42.86(9)$ & $29.17(21)$ & 13.69 \\
\hline & Caffeine beverages intake: - never & $14.29(4)$ & $33.33(24)$ & 14.28 \\
\hline & - in the past or currently & $80.95(17)$ & $80.55(58)$ & 0.40 \\
\hline \multirow{8}{*}{ 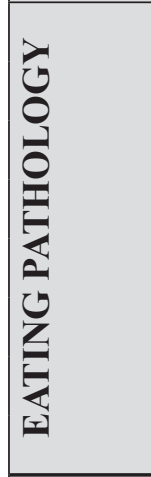 } & EAT total score & $9.0 \pm 6.6 .0$ & $10.4 \pm 7.4$ & 1.4 \\
\hline & EAT total score $\geq 20$ & $14.29(3)$ & $12.50(9)$ & 1.79 \\
\hline & Self-reported binge eating & $38.10(8)$ & $26.39(19)$ & 11.79 \\
\hline & Self-induced vomiting & - & $4.16(3)$ & 4.16 \\
\hline & Use of laxatives & $14.29(3)$ & $12.50(9)$ & 1.79 \\
\hline & Exercising more than $1 \mathrm{~h}$ daily to reduce weight & $19.05(4)$ & $13.89(10)$ & 5.16 \\
\hline & Lost weight (more than $10 \mathrm{~kg}$ ) & $19.05(4)$ & $13.89(10)$ & 5.16 \\
\hline & Treatment for ED over the preceding 6 months & $9.52(2)$ & $5.71(4)$ & 3.81 \\
\hline \multirow{5}{*}{ 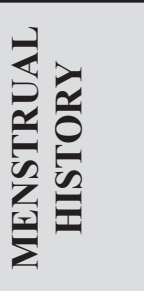 } & Primary amenorrhea & $25.00(5)$ & $3.28(2)$ & $21.72 *$ \\
\hline & Secondary amenorrhea & $20.00(4)$ & $14.75(9)$ & 5.25 \\
\hline & Oligomennorhea & $40.00(8)$ & $37.70(23)$ & 2.30 \\
\hline & Age at menarche & $14.50 \pm 1.9$ & $13.16 \pm 1.4$ & $1.34 *$ \\
\hline & Use of hormonal contraceptives & $20.00(4)$ & $24.59(15)$ & 4.59 \\
\hline
\end{tabular}

Note: The values are presented as mean $\pm S D$ or percentage (number of athletes). ${ }^{*}$ Significant difference $(p<0.05)$ between SF group and C group

Table 1 presents the comparative characteristics The athletes with and without history of SF scored of SF group and C group. The results showed no similarly on the EAT-26. The statistical analysis also significant differences in their mean age and an- found no differences in the prevalence of disturbed thropometric characteristics (weight, height and eating attitudes (EAT score $\geq 20$ ) as well as in the $\mathrm{BMI})$. The sports related factors such as training ex- presence of extreme weight control behaviors in perience, weekly training duration, participation in athletes in SFG and CG.

competitions and age at commencing competitions were also similar for both groups. Additionally, the proportions of athletes, who smoked, and used alcohol and caffeine containing beverages, did not differ significantly between SFG and CG.

Both groups differed significantly in terms of the proportion of female athletes reporting some of the menstrual irregularities studied. Primary amenorrhea reported $25 \%(n=5)$ of the athletes 
in SF groups, that is significantly higher than in C group $(3.28 \%, \mathrm{n}=2)$. The mean age of menarche for SF athletes was $14.5 \pm 1.92$ and was significantly later than for control group (13.16 \pm 1.42$)$. The use of hormonal contraceptives and prevalence of secondary amenorrhea were similar for athletes in SFG and CG.

In order to examine the potential relationship be- tween SF and possible predictors for them we calculated odds ratios. As shown in Table 2 the ratio of the odds for primary amenorrhea in athletes with and without history of SF was 10.94 . The $95 \%$ confidential interval was from 1.94 to 16.54 and the pvalue was 0.007 . For all other risk factors odds ratio with 95\% CI spun the null value and did not reach statistical significance $(\mathrm{p} \leq 0.05)$.

Table 2. Odds ratios for various risk factors for stress fractures

\begin{tabular}{|l|l|l|}
\hline \multicolumn{1}{|c|}{ RISK FACTORS } & \multicolumn{1}{|c|}{ Odds $(95 \%$ CI) } & \multicolumn{1}{c|}{ P value } \\
\hline BMI < age-matched norms & $1.06(95 \%$ CI: 0.31 to 3.70$)$ & 0.918 \\
\hline Participation in competitions & $0.53(95 \%$ CI: 0.14 to 1.97 & 0.345 \\
\hline Competitive level & 0.61 (95\% CI: 0.19 to 1.94$)$ & 0.401 \\
\hline Smoking history & $1.99(95 \%$ CI: 0.71 to 5.61$)$ & 0.192 \\
\hline Alcohol intake & $1.82(95 \%$ CI: 0.67 to 4.96$)$ & 0.241 \\
\hline Caffeine containing beverages intake & $2.13(95 \%$ CI: 0.64 to 7.02$)$ & 0.216 \\
\hline Primary amenorrhea & $10.94(95 \%$ CI: 1.94 to 16.54$)$ & 0.007 \\
\hline Secondary amenorrhea & $1.42(95 \%$ CI: 0.384 to 5.22$)$ & 0.601 \\
\hline Hormonal contraception & $0.88(95 \%$ CI: 0.25 to 3.07$)$ & 0.840 \\
\hline EAT score<20 & $1.17(95 \%$ CI: 0.285 to 4.77$)$ & 0.830 \\
\hline Self-reported binge eating & $1.72(95 \%$ CI: 0.62 to 4.78$)$ & 0.301 \\
\hline Self-induced vomiting & $0.46(95 \%$ CI: 0.02 to 9.30$)$ & 0.614 \\
\hline Use of laxatives & $1.17(95 \%$ CI: 0.29 to 4.77$)$ & 0.562 \\
\hline Exercising more than $1 \mathrm{~h}$ daily to reduce weight & $1.46(95 \%$ CI: 0.41 to 5.23$)$ & 0.830 \\
\hline Lost weight (more than $10 \mathrm{~kg})$ & $1.17(95 \%$ CI: 0.29 to 4.77$)$ & 0.562 \\
\hline Treatment for ED over the preceding 6 months & $1.79(95 \%$ CI: 0.30 to 10.53$)$ & 0.520 \\
\hline
\end{tabular}

Note: ${ }^{*} p<0.05$

\section{DISCUSSION}

In our study, we found that $22.6 \%$ of female athletes across a wide range of sports had a history of stress fractures. It would be difficult to compare this result with data from other authors, because of the heterogeneity of the groups of athletes studied. In a cross-sectional study, Duckham et al. (2012) established incidence of SF in $27 \%$ of female endurance athletes. A higher prevalence $(31 \%)$ reported Kelsey et al. (2007) for female cross-country runners. However, Wentz et al. (2011) found a much lower prevalence of SF in female athletes $(9.7 \%)$.

Due to the nature of the study, that uses a self-reported questionnaire for data collection, the exact anatomical location of the overuse injuries cannot be indicated. However, our finding that about $60 \%$ of the SF was localized at the lower limbs is consistent with data from other authors, who pointed out metatarsals and tibia as most commonly affected by stress fractures bones (Chen et al., 2013; Rizzone et al., 2017; Sharma \& Heagerty, 2017).

Undoubtedly, a numerous of intrinsic and extrinsic factors can potentially contribute to the development of stress fracture in athletes. Most of them were theoretically proposed and only a few of them were empirically proven due to inconclusive findings. The results of this study showed that no significant group differences in age, body size, BMI, and training variables between female athletes with SF and without history of SF. Some lifestyle factors such as tobacco and alcohol use and coffee consumption are considered also as risk factors for SF (Altarac et al., 2011; Lee et al., 2014).

However, our study failed to detect any association between SF and smoking, alcohol and caffeine containing beverages intake. Additionally, the calculated odds ratios for these variables were also insignif- 
icant, which does not give us a reason to accept the existence of any association between them and SF.

One of the most discussed SF risks is female athlete triad, which involves low energy availability, menstrual dysfunction and low body density. The low energy availability due to eating disturbance has been attributed to the risk of SF (Bennell et al., 1999; Cobb et al., 2007; Kelsey et al., 2007). Inadequate caloric intake may be associated with low bone density with a significant effect on the process of bone remodeling (Myburgh et al., 1990). Nevertheless, several studies failed to establish association between bone mineral density and SF (Cline et al., 1998; Frusztajer et al., 1990). EAT-26 is considered a reliable and valid instrument used for the evaluation of the tendency to exhibit ED (Garner, 1993). Our study did not identify any statistic difference between both groups in EAT-26 scores. Furthermore, the females with history of SF and the control group did not differed significantly in the proportion of athletes whose EAT-26 total score was $\geq 20$, as well as in the presence of pathological eating behaviors. The odds ratios for EAT-26 total score and psychopathological eating behaviors were also insignificant.

The menstrual disturbances, including amenorrhea, oligomenorrhea, and delayed menarche, as well as not using of oral contraceptives, may result in decrease in estrogen levels and a negative effect on bone density and are considered as predisposing factors for SF (Bennell et al., 1999; Cobb et al., 2007; Cosman et al., 2013; Shaffer et al., 2006; Nattiv, 2000). Although, most authors indicate menstrual disorders as a risk factor for stress fractures, some studies did not find association between SF and menstrual frequency or age at menarche (Armstrong et al., 2004; Lappe et al., 2011). In our study, the female athletes in both groups differed significantly only in their age at menarche and incidents of primary amenorrhea. The association between primary amenorrhea and SF risk was confirmed by calculated odds ratios. The primary amenorrhea rises 10.94 times (95\% CI: 1.94 to $61.54, \mathrm{p}=0.007$ ) the odds of having SF. Based on this result it can be concluded that late onset of menarche (after 16 years of age) increases the likelihood of SF in female athletes. There was not significant evidence to support the association between any of the other examined risk factors and stress fracture risk.
Our finding that primary amenorrhea and late onset of menarche were associated with increased risk of stress fractures is consistent with other studies carried out in athletes. This preliminary study will help to understand the stress fractures risk factors in female athletic population in Bulgaria, but more research is needed for conclusive results that can be used to develop prevention strategies.

\section{REFERENCES}

Altarac, M., Gardner, J. W., Popovich, R. M., Potter, R., et al. (2000). Cigarette smoking and exercise-related injuries among young men and women. American Journal of Preventive Medicine, Vol. 18, No. 3, Supp. 1, pp. 96-102.

Armstrong, D. W., Rue, J-P. H., Wilckens, J.H., Frassica, F. J. (2004). Stress fracture injury in young military men and women. Bone, Vol. 35 No.3, pp.806-816.

Bennell, K., Matheson, G., Meeuwisse, W., Brukner, P. (1999). Risk factors for stress fractures. Sports Medicine, Vol. 28 No. 2, pp. 91-122.

Breithaupt, M. (1855), To the pathology of the human foot. [in German] Medizinische Zeitung, Vol. 24, pp. 169. Bulathsinhala, L., Hughes, J.M., McKinnon, C.J., Kardouni, J.R., et al. (2017). Risk of stress fracture varies by race/ethnic origin in a cohort study of 1.3 million US Army soldiers. Journal of Bone and Mineral Research, Vol. 32 No. 7, pp. 1546-1553.

Chen, Y.T., Tenforde, A.S., Fredericson, M. (2013). Update on stress fractures in female athletes: epidemiology, treatment, and prevention. Current Reviews of Musculoskeletal Medicine, Vol. 6 No 2, pp. 173-181.

Cline, A.D., Jansen, G.R, Melby, C.L. (1998). Stress fractures in female army recruits: implications of bone density, calcium intake, and exercise. Journal of American College of Nutrition, Vol. 17 No. 2, pp. 128-135.

Cobb, K.L., Bachrach, L.K., Sowers, M., Nieves, J., et al. (2007). The effect of oral contraceptives on bone mass and stress fractures in female runners. Medicine and Science in Sports and Exercise, Vol. 39 No. 9, pp.1464-1473. Cosman, F., Ruffing, J., Zion, M., Uhorchak, J., et al. (2013). Determinants of stress fracture risk in United States Military Academy cadets. Bone, Vol. 55 No. 2, pp. 359-366.

Frusztajer, N.T., Dhuper, S., Warren, M.P., Brooks-Gunn, J., Fox, R.P. (1990). Nutrition and the incidence of stress fractures in ballet dancers. American Journal of Clinical Nutrition, Vol. 51 No. 5, pp. 779-783.

Garner, D.M. (1993). Self- report measures for eating disorders. Current Contents, Vol. 8 No. 8.

Garner, D.M., Olmsted, M.P, Bohr, Y., Garfinkel, P.E. 
(1982). The eating attitudes test: psychometric features and clinical correlates. Psychological Medicine, Vol. 12 No. 4, pp. 871-878.

Kelsey, J.L., Bacrach, L.K., Procter-Gray, Nieves, J., et a. (2007). Risk factors for stress fractures among young female cross-country runners, Medicine and Science in Sports and Exercise, Vol. 39 No. 9, pp. 1457-1463.

Lappe, J. M., Stegman, M. R., Recker, R. R. (2001). The impact of lifestyle factors on stress fractures in female army recruits. Osteoporosis International, Vol.12 No. 1, pp. 35-42.

Lee, D.R., Lee, J., Rota, M., Lee, J., et al. (2014). Coffee consumption and risk of fractures: a systematic review and dose-response meta-analysis. Bone, Vol. 63, pp. 20 28.

McCormick, F., Nwachukwu, B.U., Provencher, M.T. (2012). Stress fractures in runners. Clinical Sports Medicine, Vol. 31 No. 2, pp. 291-306.

Myburgh, K.H., Hutchins, J., Fataar, A.B., Hough, S.F., Noakes, T.D. (1990). Low bone density is an etiologic factor for stress fractures in athletes. Annals of Internal Medicine, Vol. 113 No.10, pp. 754-759.

Nattiv, A. (2000). Stress fractures and bone health in track and field athletes. Journal of Science and Medicine in Sports, Vol. 3 No. 3, pp. 1867-1872.

Øyen, J., Torstveit, M.K., Sundgot-Borgen, J. (2009). Self-reported versus diagnosed stress fractures in Norwegian female elite athletes. Journal of Sports Science and Medicine, Vol. 8 No. 1, pp. 130-135.

Rizzone, K.H., Ackerman, K.E., Roos, K.G., Dompier, T.P., Kerr, Z.Y. (2017). The epidemiology of stress fractures in collegiate student-athletes, 2004-2005 through 2013-2014 academic years. Journal of Athletic Training,
Vol. 52 No. 10, pp. 966-975.

Roos, K.G., Marshall, S.W., Kerr, Z.Y., et al. (2015). Epidemiology of overuse injuries in collegiate and high school athletics in the United States. American Journal of Sports Medicine, Vol. 43 No. 7, pp. 1790-1797.

Schnackenburg, K.E., Macdonald, H.M., Ferber, R., Wiley, J.P., Boyd, S.K. (2011). Bone quality and muscle strength in female athletes with lower limb stress fractures. Medicine and Science in Sports and Exercise, Vol. 43 No. 11, pp. 2110-2119.

Shaffer, R.A., Rauh, M.J., Brodine, S.K., Trone, D.W., Macera, C.A. (2006). Predictors of stress fracture susceptibility in young female recruits. American Journal of Sports Medicine, Vol. 34 No. 1, pp. 108-115.

Sharma, J., Heagerty, R., (2017). Stress Fracture: A Review of the Pathophysiology, Epidemiology and Management Options. Journal of Fractures and Sprains, Vol. 1 No. 1, pp. 1006-1015.

Snyder, R.A., Koester, M.C., Dunn, W.R. (2006). Epidemiology of stress fractures. Clinical Sports Medicine, Vol. 25 No. 1, pp. 37-52.

Wentz, L., Liu, P.Y., Haymes, E., Ilich, J.Z. (2011). Females have a greater incidence of stress fractures than males in both military and athletic populations: a systemic review. Military Medicine, Vol. 176 No. 4, pp. 420430.

\section{Corresponding author:}

Diana Dimitrova,

Professor, $\mathrm{MD}, \mathrm{PhD}$,

National Sports Academy „Vassil Levski”

21, Acad. Stefan Mladenov str.

1117 Sofia, Bulgaria

E-mail:dianansa@yahoo.com 